\title{
Erratum to: Withania somnifera extract attenuates stem cell factor-stimulated pigmentation in human epidermal equivalents through interruption of ERK phosphorylation within melanocytes
}

Hiroaki Nakajima · Katsunori Fukazawa •

Yuki Wakabayashi · Kazumasa Wakamatsu •

Genji Imokawa

Published online: 25 January 2013

(c) The Japanese Society of Pharmacognosy and Springer Japan 2013

Erratum to: J Nat Med (2012) 66:435-446

DOI 10.1007/s11418-011-0604-0

In the original publication of the article, a part of Fig. 1d was published incorrectly. The corrected version is given below.

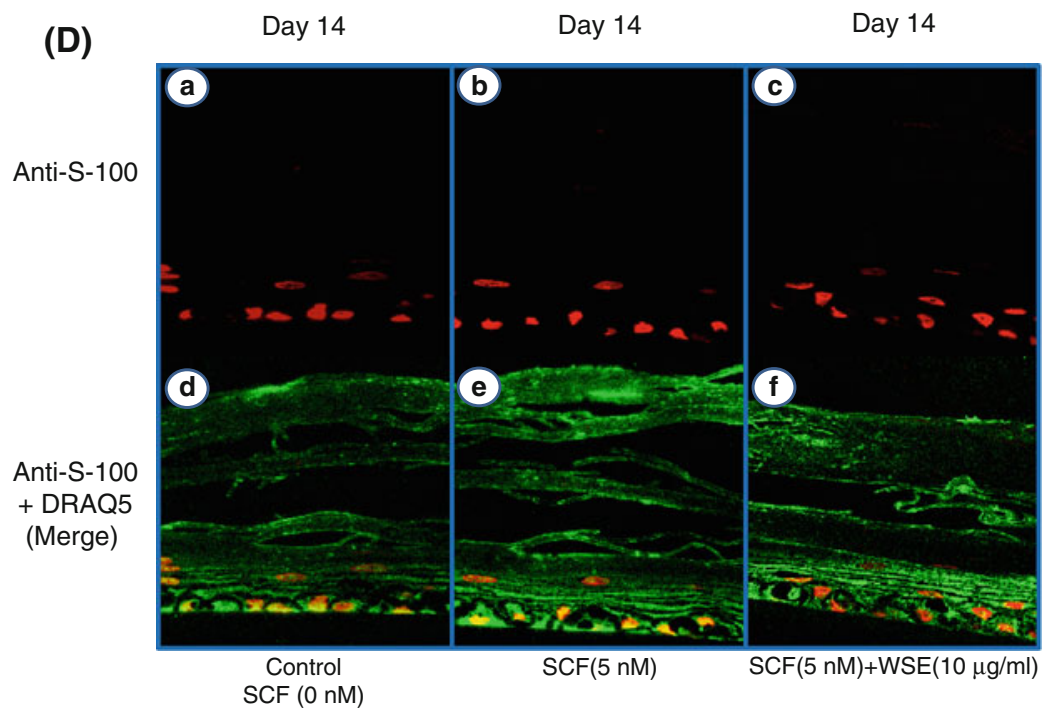

The online version of the original article can be found under doi:10.1007/s11418-011-0604-0.

H. Nakajima · K. Fukazawa · Y. Wakabayashi

G. Imokawa $(\bowtie)$

School of Bioscience and Biotechnology,

Tokyo University of Technology,

1404-1 Katakura, Hachioji, Tokyo 192-0982, Japan

e-mail: imokawag@dream.ocn.ne.jp

K. Wakamatsu

School of Health Sciences, Fujita Health University,

Toyoake, Japan 